\title{
Consequences of Nigrostriatal Denervation on the Functioning of the Basal Ganglia in Human and Nonhuman Primates: An In Situ Hybridization Study of Cytochrome Oxidase Subunit I mRNA
}

\author{
Miquel Vila, ${ }^{1}$ Richard Levy, ${ }^{1}$ Maria-Trinidad Herrero, ${ }^{2}$ Merle Ruberg, ${ }^{1}$ Baptiste Faucheux, ${ }^{1}$ José A. Obeso, ${ }^{3}$ \\ Yves Agid, ${ }^{1}$ and Etienne C. Hirsch ${ }^{1}$ \\ 1/nstitut National de la Santé et de la Recherche Médicale U289, Hôpital de la Salpêtrière, 75013 Paris, France, \\ ${ }^{2}$ Department of Anatomy, University of Murcia, 30071 Murcia, Spain, and ${ }^{3}$ Department of Neurology and Functional \\ Neurosurgery, Quiron Clinic, 20012 San Sebastian, Spain
}

\begin{abstract}
To examine the consequences of nigrostriatal denervation and chronic levodopa (L-DOPA) treatment on functional activity of the basal ganglia, we analyzed, using in situ hybridization, the cellular expression of the mRNA encoding for cytochrome oxidase subunit I (COI mRNA), a molecular marker for functional neuronal activity, in the basal ganglia. This analysis was performed in monkeys rendered parkinsonian by 1-methyl-4-phenyl-1,2,3,6tetrahydropyridine (MPTP) intoxication, some of which had been receiving L-DOPA, and in patients with Parkinson's disease (PD). In MPTP-intoxicated monkeys compared with control animals, COI mRNA expression was increased in the subthalamic nucleus (STN) and in the output nuclei of the basal ganglia, i.e., the internal segment of the globus pallidus and the substantia nigra pars reticulata. This increase was partially reversed by L-DOPA treat-
\end{abstract}

ment. COI mRNA expression remained unchanged in the external segment of the globus pallidus (GPe). In PD patients, all of whom had been treated chronically by L-DOPA, COI mRNA expression in the analyzed basal ganglia structures was similar to that in control subjects. These results are in agreement with the accepted model of basal ganglia organization, to the extent that the output nuclei of the basal ganglia are considered to be overactive after nigrostriatal denervation, partly because of increased activity of excitatory afferents from the STN. Yet, our results would also seem to contradict this model, because the overactivity of the STN does not seem to be attributable to a hypoactivation of the GPe.

Key words: Parkinson's disease; 1-methyl-4-phenyl-1,2,3,6tetrahydropyridine; L-DOPA; cytochrome oxidase; in situ hybridization; basal ganglia
The progressive loss of dopaminergic neurons in the substantia nigra pars compacta occurring in Parkinson's disease (PD) provokes a cascade of functional changes in the basal ganglia circuitry, which are though to participate in the development of the symptoms of the disease (Albin et al., 1989; Crossman, 1989; Alexander and Crutcher, 1990; DeLong, 1990). Indeed, as a result of dopaminergic nigrostriatal denervation, the activity of the basal ganglia output nuclei, the internal segment of the globus pallidus (GPi), and the substantia nigra pars reticulata (SNpr) is increased by two simultaneous but distinct mechanisms: first, hypoactivation of a direct inhibitory input from the striatum, and second, an increase in excitatory input from the subthalamic nucleus (STN), which is thought to result from release of the tonic inhibitory control normally exerted by the GABA-containing neurons in the external segment of the globus pallidus (GPe) on STN neurons. The increased activity of GPi and SNpr neurons, which mainly project to the thalamus and use the inhibitory amino acid GABA as a transmitter, leads in turn to an increased inhibition of thalamocortical neurons, which are excitatory and probably glutamatergic. It is thought that this decreased thalamocortical feed-

\footnotetext{
Received Aug. 5, 1996; revised Oct. 28, 1996; accepted Oct. 29, 1996.

This study was supported by Institut National de la Santé et de la Recherche Médicale (France), National Parkinson's Disease Foundation (Miami, FL), Spanish government (Grant SAF 94-1392) (Spain), and the Ministère de l'Enseignement Supérieur et de la Recherche (France). We thank Drs. J.-J. Hauw, C. Duyckaerts, and $\mathrm{O}$. Rascol for their help in providing brain specimens.

Correspondence should be addressed to Dr. E. C. Hirsch, Institut National de la Santé et de la Recherche Médicale U289, Hôpital de la Salpêtrière, 47 Boulevard de l'Hôpital, 75013 Paris, France.

Copyright (C) 1997 Society for Neuroscience $0270-6474 / 97 / 170765-09 \$ 05.00 / 0$
}

back is responsible for many of the clinical manifestations of PD (Albin et al., 1989; Crossman, 1989; Klockgether and Turski, 1989; DeLong, 1990).

Changes in the functioning of the basal ganglia circuitry after nigrostriatal denervation have been detected by electrophysiological recordings (Wichmann and DeLong, 1993), metabolic studies using the 2-deoxyglucose method (Mitchell et al., 1989), and biochemical analyses. Most of these biochemical studies were based on the estimation of the cellular expression of the messenger RNA coding for the $67 \mathrm{kDa}$ isoform of glutamic acid decarboxylase $\left(\mathrm{GAD}_{67} \mathrm{mRNA}\right)$, the synthetic enzyme of GABA, as an indirect marker of GABAergic activity within the basal ganglia, because most basal ganglia structures use GABA as neurotransmitter (Soghomonian and Chesselet, 1992; Chesselet et al., 1993; Soghomonian et al., 1994; Levy et al., 1995; Herrero et al., 1996; Vila et al., 1996a). More recently, another biochemical marker has been introduced to study the changes in the overall metabolic activity of the different basal ganglia structures after nigrostriatal denervation in 6-hydroxydopamine-lesioned rats (Porter et al., 1994) and in 1-methyl-4-phenyl-1,2,3,6tetrahydropyridine (MPTP)-intoxicated monkeys (Vila et al., 1996b). This method is based on the regional analysis of the histochemical activity of cytochrome oxidase (CO), the terminal enzyme in the mitochondrial electron transport chain, because several studies have indicated that $\mathrm{CO}$ activity is linked directly to neuronal activity (for review, see Wong-Riley, 1989). This method allows an analysis of global changes in functional activity of neurons, even when markers of the neurotransmission are not available; however, the relative contributions to regional $\mathrm{CO}$ 
histochemical activity of cell bodies and dendrites of intrinsic neurons or terminals from afferent neurons still remain to be determined. Unlike $\mathrm{CO}$ enzymatic activity that is expressed in neuronal perikarya, dendrites, and terminals, the mRNA coding for both nuclear and mitochondrial subunits of $\mathrm{CO}$ is concentrated mainly in neuronal cell bodies (Hevner and Wong-Riley, 1991). In this study, we analyzed specifically the functional activity of intrinsic neurons in the output system of the basal ganglia and in two basal ganglia regulatory structures, the STN and the GPe, after nigrostriatal denervation, using the expression of the messenger RNA coding for $\mathrm{CO}$ mitochondrial-derived subunit I as a marker for neuronal activity at the cellular level. This study was performed by quantitative in situ hybridization in monkeys rendered parkinsonian by MPTP intoxication, some of which had been receiving L-DOPA, and in patients with $\mathrm{PD}$, all of whom had been receiving L-DOPA treatment.

\section{MATERIALS AND METHODS}

Experimental animals. All studies were carried out in accordance with the Declaration of Helsinki and the Guide for the Care and Use of Laboratory Animals adopted and promulgated by National Institutes of Health.

Ten adult cynomolgus monkeys (Macaca fascicularis; purchased from Charles River), aged 8-10 years, were studied. Three neurotoxin-free animals were used as controls, and the other seven received chronic treatment with high doses of MPTP $(0.5 \mathrm{mg} / \mathrm{kg}$ MPTP hydrochloride/ $0.9 \%$ sodium chloride, i.v., once a week, under ketamine anesthesia) until a stable parkinsonian syndrome was achieved (cumulative doses: $0.5-5.3$ $\mathrm{mg} / \mathrm{kg}$ ). Three MPTP-intoxicated monkeys received L-DOPA therapy. L-DOPA ( $50 \mathrm{mg} / \mathrm{kg}$, p.o.) was given twice a day, starting immediately after MPTP treatment had been completed and until the animals were killed. L-DOPA therapy improved the motor status of the animals and provoked dyskinesias. The animals were killed $90 \mathrm{~d}$ after the acute effect of the last MPTP injection, to ensure the absence of any motor recovery.

Human subjects. The study was performed on postmortem brain tissue from four control subjects with no history of neurological or psychiatric illness and from four patients with idiopathic Parkinson's disease. All parkinsonian patients had been treated with L-DOPA, at a mean daily dose ranging between 200 and $1250 \mathrm{mg}$ at the final stage of the disease. In all patients, motor disability was improved by long-term L-DOPA therapy. The diagnosis of Parkinson's disease was confirmed on neuropathological examination by the presence of Lewy bodies in the substantia nigra and locus ceruleus and by severe neuronal loss in the substantia nigra.

There were no significant differences between controls and parkinsonian patients in terms of mean age at death (controls, $82.3 \pm 3.7$ years; parkinsonian patients, $73.7 \pm 3.2$ years) and interval from death to freezing (controls, $18.5 \pm 2.3 \mathrm{hr}$; parkinsonian patients: $19.4 \pm 3.6 \mathrm{hr}$ ).

Tissue preparation. Immediately after death in monkeys and within $2 \mathrm{hr}$ of autopsy in humans, the brains were hemisected along the midline, and the brainstem was removed from the rest of the brain. The cerebral hemispheres were cut into $1.5 \mathrm{~cm}$ slabs along the frontal plane. Blocks containing the pallidal complex were dissected from the slabs and together with the brainstem were frozen rapidly in powdered dry ice. Twenty-micron sections were cut at $-20^{\circ} \mathrm{C}$, with use of a cryostat (Reichert, Heidelberg, Germany), in the frontal plane for the pallidal complex and transversely for the mesencephalon. Sections were thawmounted on gelatin-double-coated slides and stored at $-80^{\circ} \mathrm{C}$ until they were processed.

In situ hybridization. In situ hybridization with a $\left[{ }^{35} \mathrm{~S}\right]-$ labeled cRNA probe was performed as described previously (Chesselet et al., 1987; Javoy-Agid et al., 1990). A cRNA probe was synthesized from a doublestranded DNA fragment, corresponding to nucleotides 5999-6925 of the human mitochondrial genome (EMBO databank, reference MIHSCG) within the gene coding for CO subunit I (COI), produced by PCR and subcloned in the pGEM-T vector (Promega, Madison, WI). Sense and antisense probes were transcribed from $1 \mu \mathrm{g}$ plasmid, as described by Fontaine et al. (1988).

Unfixed slide-mounted frozen sections were post-fixed for $5 \mathrm{~min}$ in $3 \%$ paraformaldehyde $(\mathrm{w} / \mathrm{v})$ and then acetylated with $0.25 \%$ acetic anhydride in $0.1 \mathrm{~mm}$ ethanolamine, followed by $0.1 \mathrm{~m}$ Tris-glycine treatment for 30 min and dehydration through graded ethanols. Sections were incubated for $3.5 \mathrm{hr}$ at $50^{\circ} \mathrm{C}$ in a humid chamber with $50 \mu \mathrm{l}$ of hybridization solution containing either the antisense or the sense $\left[{ }^{35} \mathrm{~S}\right]$-labeled cRNA probe $\left(2.5 \times 10^{6} \mathrm{cpm}\right)$. After hybridization, sections were washed at $50^{\circ} \mathrm{C}$ in $50 \%$ formamide $/ 2 \times \mathrm{SSC}$, incubated for $30 \mathrm{~min}$ at $37^{\circ} \mathrm{C}$ with $\mathrm{RNase} \mathrm{A}$ $(100 \mu \mathrm{g} / \mathrm{ml}$ in $2 \times \mathrm{SSC})$ to digest unhybridized probe, rinsed again at $50^{\circ} \mathrm{C}$ in $50 \%$ formamide $/ 2 \times \mathrm{SSC}$, and then washed overnight at room temperature. After a final rinse in $2 \times \mathrm{SSC}$, the sections were dehydrated in graded ethanol solutions (70, 80, and 95\%) prepared with $300 \mathrm{~mm}$ ammonium acetate, delipidated in xylene, rinsed in ethanol $100 \%$, and air-dried. Autoradiograms were generated by exposing the slides to x-ray films (Hyperfilm $\beta$ max; Amersham, Arlington Heights, IL) for $1 \mathrm{~d}$ to 3 weeks at room temperature. Sections were then dipped in NTB-2 emulsion (Kodak, Integra Biosciences), diluted 1:1, air-dried, and stored at $4^{\circ} \mathrm{C}$ in lightproof boxes for $1-8$ weeks. Exposed slides were developed in Kodak D-19 for $4 \mathrm{~min}$ at $15^{\circ} \mathrm{C}$, and counterstained with hematoxylin $0.1 \%$ $(w / v)$ to localize cell nuclei. Each experiment was duplicated, each time using two sections per subject for each labeling and a newly synthesized probe.

Data analysis. Results were quantified by computer-assisted image analysis (Histo 200, Biocom). The number of silver grains over the neuronal cell body was estimated under polarized light by measuring optical density with respect to a standard curve of a defined number of silver grains. Grain density (number of silver grains per surface area of the neuron) was then calculated. Nonspecific labeling was estimated with sense probes. Background labeling, estimated at a distance from labeled cells, was subtracted from total labeling.

In both monkeys and humans, the analysis was performed in the GPi, the GPe, the STN, and the SNpr, on 50 randomly distributed labeled neurons per structure. Mean values of COI mRNA expression level were obtained for the whole structures as well as for five arbitrarily subdivided medial to lateral subregions. The striatum was not analyzed, because it is composed of several populations of neurons belonging to different neuronal systems (interneurons, neurons from the direct and indirect pathways) that require identification of the different types of neuron.

To delimit the boundaries of the different basal ganglia structures, acetylcholinesterase histochemistry was performed on adjacent sections according to the Geneser-Jensen and Blackstad method, as modified by Graybiel and Ragsdale (1978).

Statistical analysis in monkeys and humans was performed by two-way ANOVA, taking as factors the different group of monkeys (controls, MPTP-intoxicated, and MPTP-intoxicated treated by L-DOPA) or humans (control subjects, parkinsonian patients), the regions studied, and the group-region interaction, and was followed by post hoc analysis for intergroup comparisons. The null hypothesis was rejected at an $\alpha$ risk of $5 \%$. Separate analyses were performed for monkeys and for humans. All of the analyses were performed blind to the source of the tissue.

\section{RESULTS}

\section{Pattern of COI mRNA expression}

The antisense COI cRNA produced a specific and reproducible pattern of hybridization in monkeys and humans, although the autoradiographic signal was less intense in monkeys than in human autopsy material, both on film autoradiograms and on emulsioned sections. In both monkey and human controls, the signal at the regional level on autoradiographic films was more intense in the SNpr and STN than in the globus pallidus (Fig. 1). At the cellular level, on emulsion-coated sections, COI mRNA expression was highest in the globus pallidus, intermediate in the SNpr, and lowest in the STN (Figs. 2, 3). Control sections, which were hybridized with the sense probe, did not show labeling above uniform background levels on the film autoradiograms or, at the microscopic level, on the emulsion-coated sections. Exposure time was shorter for human material (7-10 d) than for monkeys (3-4 weeks). Examination of hematoxylin-counterstained sections at high magnification using bright-field optics showed that COI mRNA was concentrated in the neuronal cell bodies, whereas glial cells contained little of the transcript. 

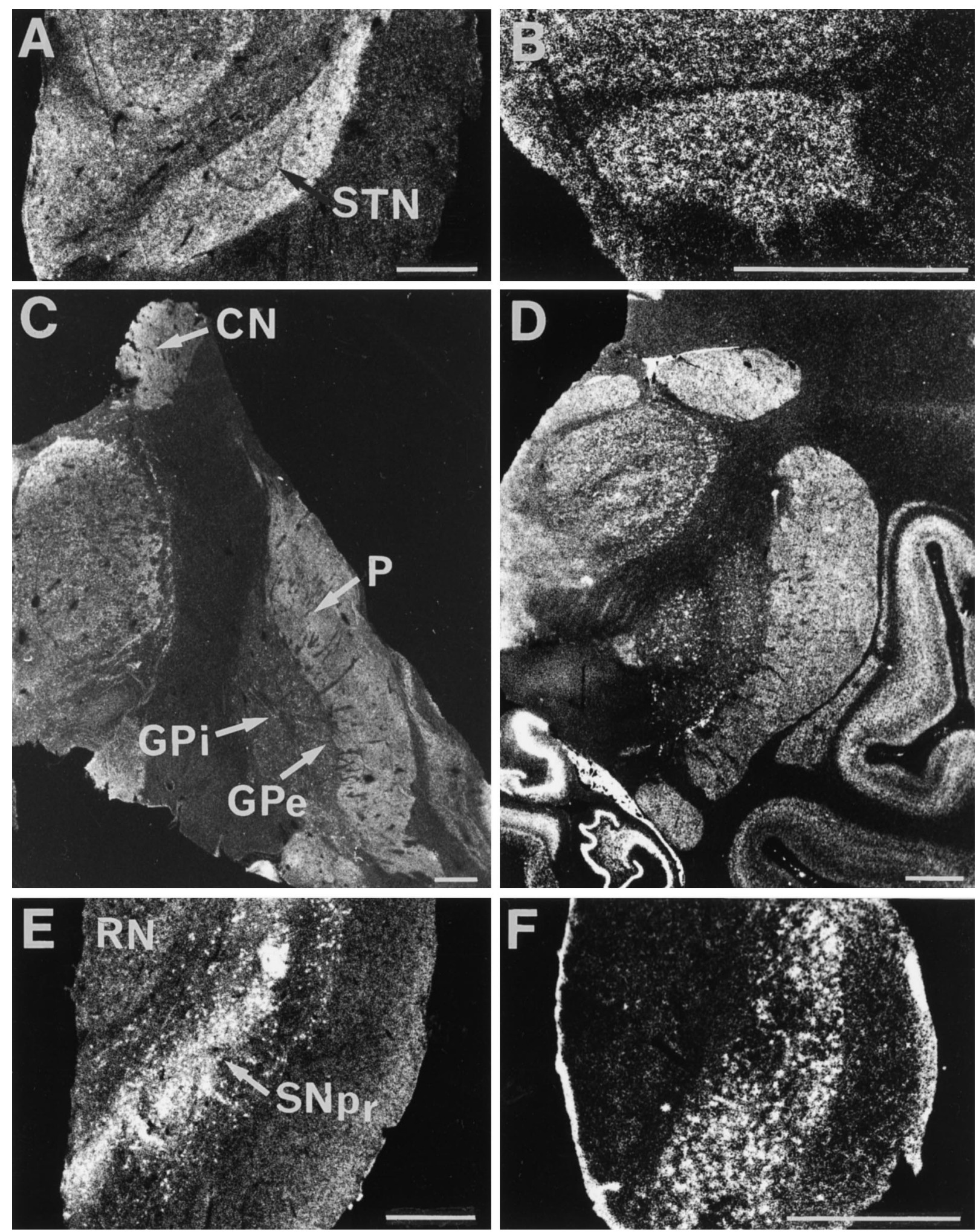

Figure 1. Film autoradiograms of COI mRNA in situ hybridization in the mesencephalon and basal ganglia of monkeys $(B, D, F)$ and humans $(A$, $C$, $E$ ). In situ hybridization was performed with antisense COI mRNA probes. $C N$, Caudate nucleus; GPe, external segment of the globus pallidus; $G P i$, internal segment of the globus pallidus; $P$, putamen; $R N$, red nucleus; $S N p r$, substantia nigra pars reticulata; $S T N$, subthalamic nucleus. Scale bars, $0.25 \mathrm{~cm}$. 

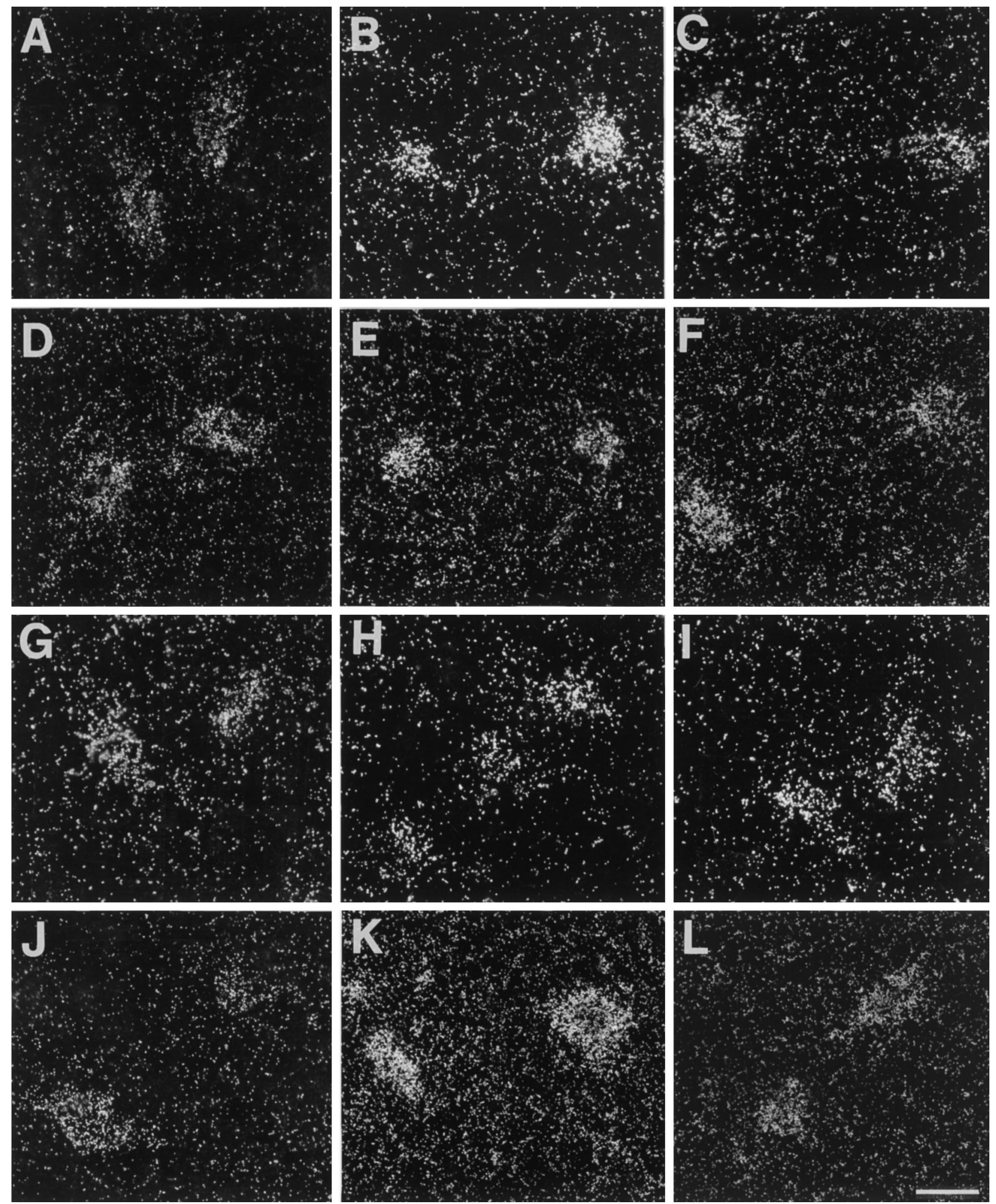

Figure 2. Photomicrographs of neurons labeled by COI mRNA in situ hybridization, viewed under polarized light illumination, in the subthalamic nucleus $(A-C)$, internal segment of the globus pallidus $(D-F)$, external segment of the globus pallidus $(G-I)$, and the substantia nigra pars reticulata ( $J-L)$ of a control monkey $(A, D, G, J)$, an MPTP-intoxicated monkey $(B, E, H, K)$, and an MPTP-intoxicated monkey receiving L-DOPA treatment $(C, F, I$, $L)$. COI mRNA expression was increased in the subthalamic nucleus, internal segment of the globus pallidus, and substantia nigra pars reticulata of MPTP-intoxicated monkeys compared with control animals. This increase was partially reversed by L-DOPA treatment. Scale bar, $20 \mu \mathrm{m}$. 

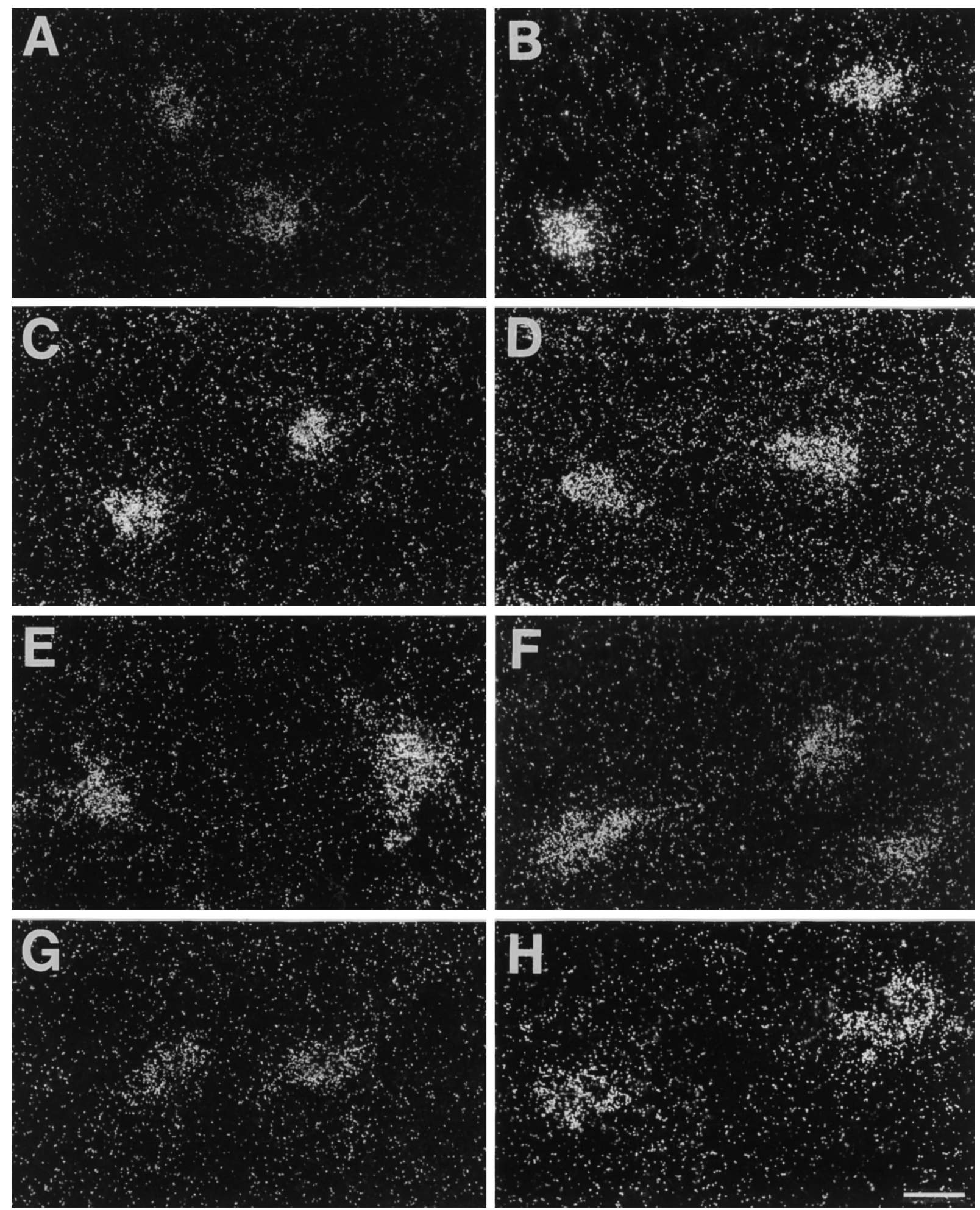

Figure 3. Photomicrographs of neurons labeled by COI mRNA in situ hybridization, viewed under polarized light illumination, in the subthalamic nucleus $(A, B)$, internal segment of the globus pallidus $(C, D)$, external segment of the globus pallidus $(E, F)$, and the substantia nigra pars reticulata $(G$, $H)$ of a human control subject $(A, C, E, G)$ and a parkinsonian patient $(B, D, F, H)$. Scale bar, $20 \mu \mathrm{m}$.

\section{COI mRNA expression in MPTP-intoxicated monkeys}

In MPTP-intoxicated monkeys, mean silver grain density over the labeled cells was significantly increased compared with that of control animals $\left(F_{(2,28)}=21.47 ; p=0.0001\right)$. Inter-regional dif- ferences were not statistically significant. In MPTP-intoxicated monkeys, COI mRNA expression was increased markedly in the STN compared with control animals $(+100 \% ; p<0.01)$ and in the output nuclei of the basal ganglia: GPi $(+91 \% ; p<0.05)$ and 
SNpr $(+104 \% ; p<0.01)$. In the GPe, COI mRNA expression tended to be increased in MPTP-intoxicated monkeys compared with control animals, even if it was not statistically significant $(+66 \% ; p=0.06)$. L-DOPA therapy partially reversed the increased COI mRNA expression in the output nuclei of the basal ganglia, with a minor effect on STN activity (Table 1, Fig. 2). No differences in COI mRNA expression were found between the medial and lateral subdivisions of the studied regions.

\section{COI mRNA expression in parkinsonian patients}

In patients with $\mathrm{PD}$, who had all been treated chronically by L-DOPA, COI mRNA expression was similar to that of control subjects in all of the basal ganglia structures analyzed $\left(F_{(1,22)}=\right.$ $2.32 ; p=0.14$ ) (Table 1, Fig. 3) and in their subdivisions. Consequently, no post hoc analysis was performed, even if in the STN an increase in COI mRNA expression was found in parkinsonian patients compared with control subjects $(+74 \%)$ (Table 1, Fig. 3).

\section{DISCUSSION}

\section{Specificity of the labeling}

The specificity of the in situ hybridization signal in the monkey and in humans is supported by (1) the low levels of diffuse background labeling obtained with the sense probe, contrasting with the high labeling observed with the antisense probe in the different basal ganglia structures of both monkeys and humans; (2) the similar intensity and regional distribution of the labeling on duplicate sections in the same experiments and in independent experiments; (3) the localization of the silver grains, at the light microscopic level, over neuronal perikarya in sections hybridized with the antisense probe and the low level of expression of COI mRNA in glial cells, as described previously by Hevner and Wong-Riley (1991); and (4) the regional distribution of labeling obtained with the antisense probe, corresponding to that described previously in rat, monkey, and human brains for COI mRNA, CO activity, and CO protein (Hevner and Wong-Riley, 1991, 1995; Vila et al., 1996b). In both monkey and human controls, the signal at the regional level on autoradiographic films was more intense in the SNpr and STN than in the globus pallidus, in agreement with the regional distribution of $\mathrm{CO}$ histochemical activity described previously in rat, monkey, and human brains (Hevner and Wong-Riley, 1995; Vila et al., 1996b). This heterogeneous distribution on film autoradiograms probably results from differences in cell density in the various structures analyzed. On emulsioned sections, COI mRNA expression at the cellular level in both monkey and human controls was highest in the globus pallidus, intermediate in the SNpr, and lowest in the STN, in agreement with the reported spontaneous activity of these structures detected by electrophysiological recordings (Miller and Delong, 1987; Wichmann et al., 1994).

\section{Significance of COI mRNA expression}

The use of the mitochondrial enzyme $\mathrm{CO}$ as a metabolic marker for neuronal functional activity is now well established (for review, see Wong-Riley, 1989). Indeed, the activity of this enzyme is regulated by changes in the synaptic firing pattern (Hevner et al., 1992), and it is responsive to alterations in neuronal activity (Wong-Riley et al., 1978; Wong-Riley, 1979; Wong-Riley and Welt, 1980; Wong-Riley and Carroll, 1984; Hevner and WongRiley, 1991; Porter et al., 1994; Vila et al., 1996b). Experimentally induced changes in $\mathrm{CO}$ activity are accompanied by parallel changes in $\mathrm{CO}$ protein levels and nuclear- and mitochondrialencoded CO subunit mRNA levels (Hevner and Wong-Riley,
1990, 1991). Thus, it is likely that CO activity is regulated mainly at the level of protein amount rather than molecular activity, implying that regulation of gene expression is the primary mechanism of $\mathrm{CO}$ activity regulation in neurons (Hevner and WongRiley, 1991). Mammalian CO is composed of 13 subunits, three of which (I, II, and III) are encoded by mitochondrial genes and the other 10 by nuclear genes (Kadenbach et al., 1983, 1987). The catalytic core of the enzyme is composed mainly of the mitochondrially synthesized subunits, whereas the function of the nuclearencoded subunits is unclear (Wong-Riley, 1989). Even if CO biosynthesis involves the coordinated expression of the two genomes, it has been reported that in neurons, mitochondrialderived subunit I mRNA is regulated more tightly by neuronal activity than nuclear-encoded CO subunits (Hevner and WongRiley, 1993) and is therefore a reliable index, on histological preparations, of the relative activities of different populations of neurons. Other markers have also been used to study energy metabolism in the brain, particularly 2-deoxyglucose (2-DG) autoradiography (Porrino et al., 1987; Mitchell et al., 1989, 1992). Even if both $\mathrm{CO}$ and $2-\mathrm{DG}$ are positively related to neuronal activity, there is a little correlation between the two methods. This apparent discrepancy may relate to inherent technical differences between both methods rather than indicate different patterns of neuronal activity. Indeed, compared with 2-DG autoradiography, the expression of COI mRNA (1) reflects the oxidative metabolic needs during a longer lasting period of neuronal activity than 2-DG uptake, (2) is related to functional activity of intrinsic neurons rather than terminals from afferent neurons, and (3) allows an analysis at the cellular level. Thus, COI mRNA expression can be considered a good index of steady-state long-term functional activity at the cellular level in specific areas of the brain.

\section{Expression of COI mRNA in the basal ganglia of MPTP-intoxicated monkeys}

In MPTP-intoxicated monkeys, the expression of COI mRNA was significantly increased compared with control animals in neurons of the STN and the output nuclei of the basal ganglia, GPi and SNpr, suggesting that their activity increased after nigrostriatal denervation. The increase in COI mRNA expression was partially reversed by L-DOPA therapy in the affected structures, confirming its modulation by dopaminergic input. These results are in agreement with the accepted model of basal ganglia organization, in which the basal ganglia output nuclei are considered to become hyperactive after nigrostriatal denervation, partly because of increased stimulation by excitatory afferents from the STN (Miller and DeLong, 1987; Albin et al., 1989; Mitchell et al., 1989; DeLong, 1990; Wichmann and DeLong, 1993; Bergman et al., 1994), as a consequence of the hypoactivation of GABAergic neurons of the GPe. In our study, however, COI mRNA expression not only was not decreased in the GPe of MPTP-intoxicated monkeys, but it even tended to be increased compared with control animals. This may reflect an increased excitatory influence to the GPe arising from the hyperactive STN. The effect of dopaminergic lesions on the GPe is highly controversial (for reviews, see Chesselet and Delfs, 1996; Levy et al., 1997). In agreement with our results, several studies previously reported unchanged or even increased levels of $\mathrm{GAD}_{67}$ mRNA in the GPe after nigrostriatal denervation in 6-hydroxydopamine-lesioned rats (Kincaid et al., 1992; Soghomonian and Chesselet, 1992) and MPTP-intoxicated monkeys (Soghomonian et al., 1994; Herrero et al., 1996). At the electrophysiological level, even if a decreased 
Table 1. Estimated levels of COI mRNA expression detected by in situ hybridization in basal ganglia and mesencephalon of monkeys and humans

\begin{tabular}{lllll} 
& GPe & GPi & STN & SNpr \\
\hline $\begin{array}{l}\text { Monkeys } \\
\text { Controls }\end{array}$ & $0.77 \pm 0.10$ & $0.81 \pm 0.10$ & $0.61 \pm 0.12$ & $0.71 \pm 0.05$ \\
MPTP & $1.28 \pm 0.15$ & $1.55 \pm 0.16^{a}$ & $1.22 \pm 0.03^{c}$ & $1.45 \pm 0.15^{c}$ \\
MPTP + & & & & \\
$\quad$ L-DOPA & $0.94 \pm 0.19$ & $0.96 \pm 0.12^{b}$ & $0.89 \pm 0.20$ & $0.96 \pm 0.10^{d}$ \\
Humans & & & & \\
$\quad$ Controls & $1.50 \pm 0.18$ & $1.59 \pm 0.24$ & $1.07 \pm 0.10$ & $1.32 \pm 0.09$ \\
PD patients & $1.40 \pm 0.32$ & $1.60 \pm 0.37$ & $1.87 \pm 0.04$ & $1.50 \pm 0.20$
\end{tabular}

Estimation of COI mRNA levels detected by in situ hybridization in basal ganglia and mesencephalic structures in monkeys (control, MPTP-intoxicated, and MPTPintoxicated receiving L-DOPA treatment) and humans (control subjects and PD patients). COI mRNA levels were estimated by hybridization of $\left.{ }^{35} \mathrm{~S}\right]$-labeled cRNA and expressed as silver grain density (grains $/ \mu \mathrm{m}^{2}$ ) over labeled cells. Values represent the mean \pm SEM. Fifty neurons were evaluated in each structure in each subject. ${ }^{a} p<0.05$ compared with controls; ${ }^{b} p<0.05$ compared with MPTP intoxicated monkeys; ${ }^{c} p<0.01$ compared with controls; ${ }^{d} p=0.05$ compared with MPTP-intoxicated monkeys. GPe, External segment of the globus pallidus; GPi, internal segment of the globus pallidus; SNpr, substantia nigra pars reticulata; STN, subthalamic nucleus.

neuronal activity in the GPe of MPTP-intoxicated monkeys has been reported (Miller and DeLong, 1987; Filion and Tremblay, 1991), other studies in monkeys and rats did not find any decrease, or found only a slight but not statistically significant decrease, in the tonic activity of GPe neurons after destruction of the nigrostriatal pathway (Filion, 1979; Montgomery et al., 1985; Pan and Walters, 1988; Hassani et al., 1996). Moreover, Hassani et al. (1996) showed in rodents that removal of pallidal input to the STN by the direct destruction of the globus pallidus (the rodent homolog of GPe) induced only a slight increase in the firing rate of subthalamic neurons $(+19.5 \%)$, compared with that caused by lesion of nigral dopaminergic pathway with 6-hydroxydopamine $(+105.7 \%)$. Taken together, these data suggest that the overactivity of the STN after loss of dopaminergic innervation is not mediated solely by the GPe, consistent with our results. An alternative explanation accounting for the STN hyperactivity occurring in parkinsonism is needed. According to anatomical and biochemical data, one may hypothesize that the excitatory corticosubthalamic and/or thalamosubthalamic projections might contribute to the increased activity of STN neurons after nigrostriatal denervation. The excitatory glutamatergic projection from the centromedian-parafascicular nucleus of the thalamus to the STN has been reported to drive the spontaneous subthalamic firing rate (Mouroux and Féger, 1993; Mouroux et al., 1995). It has also been hypothesized that dopaminergic depletion could lead to increased activity of the excitatory glutamatergic projection from the cerebral cortex to the STN (Hassani et al., 1996). Another possibility is that dopamine depletion might directly affect STN activity (Delfs et al., 1995; Chesselet and Delfs, 1996; Levy et al., 1996). Indeed, anatomical and pharmacological data indicate that STN neurons can be regulated by a direct dopaminergic projection from the substantia nigra pars compacta (Parent and Lavoie, 1993; Johnson et al., 1994; Ruskin and Marshall, 1995; Kreiss et al., 1996); however, the effect of the release from this dopaminergic innervation remains controversial (Campbell et al., 1985; Mintz et al., 1986; Johnson et al., 1994). Thus, little is known about the functional modifications occurring in these circuits after dopaminergic denervation, and more studies are needed to clarify this point. The understanding of subthalamic function regulation is all the more important, because it is likely that STN hyperactivity plays a critical role in the pathophysiology of PD. Indeed, it has been demonstrated that subthalamotomy or inhibitory subthalamic stimulation can ameliorate the clinical symptomatology of PD (Bergman et al., 1990; Aziz et al., 1991; Sellal et al., 1992; Benazzouz et al., 1993; Guridi et al., 1996).

\section{Expression of COI mRNA in the basal ganglia of parkinsonian patients}

As in MPTP-intoxicated monkeys receiving L-DOPA, COI mRNA expression in the basal ganglia structures of patients with PD, all of whom had been treated chronically with the drug, was unchanged compared with control subjects. This is consistent with previous studies using histochemical evaluations of $\mathrm{CO}$ activity or the levels of expression of $\mathrm{GAD}_{67}$ mRNA to assess the activity of neurons in the basal ganglia of PD patients compared with control subjects (Levy et al., 1995; Herrero et al., 1996; Vila et al., 1996a,b); however, COI mRNA levels in the STN of parkinsonian patients were increased compared with control subjects, although the increase did not reach the level of significance observed in MPTP-intoxicated monkeys. A likely explanation is that L-DOPA modifies GPi and SNpr through both the STN and the direct striato-pallido-nigral circuit, thus having a more profound effect on GPi and SNpr than on STN. It is possible that the partial failure of L-DOPA to normalize STN activity in PD might account for the persistence of some motor problems, such as freezing of gait.

Alternatively, chronic nigrostriatal denervation in PD, compared with acute denervation in MPTP-intoxicated monkeys, might result in normalization of COI mRNA expression in parkinsonian patients. Indeed, GABAergic activity in the SNpr and GPi of 6-hydroxydopamine-lesioned rats spontaneously returned to control levels after a transient increase (Vernier et al., 1988). Thus, it may well be that the activity of the STN and basal ganglia output structures increases transiently at early stages of the disease and tends to normalize as the disease evolves. The combination of chronic nigrostriatal denervation and chronic L-DOPA therapy thus may lead to an unchanged COI mRNA expression in the basal ganglia of parkinsonian patients.

In summary, we have shown that COI mRNA expression is a useful marker for neuronal activity in the basal ganglia of both monkeys and humans. Our findings provide further support for the existence of increased activity of the GPi and SNpr in the parkinsonian state and for the crucial role of the STN as a driving force in the basal ganglia.

\section{REFERENCES}

Albin RL, Young AB, Penney JB (1989) The functional anatomy of basal ganglia disorders. Trends Neurosci 12:366-375.

Alexander GE, Crutcher MD (1990) Functional architecture of the basal ganglia circuits: neural substrates of parallel processing. Trends Neurosci 13:266-271.

Aziz TZ, Peggs D, Sambrook MA, Crossman AR (1991) Lesions of the subthalamic nucleus for the alleviation of 1-methyl-4-phenyl-1,2,3,6tetrahydropyridine (MPTP)-induced parkinsonism in the primate. Mov Disord 4:288-292.

Benazzouz A, Gross C, Feger J, Boraud T, Bioulac B (1993) Reversal of rigidity and improvement in motor performance by subthalamic highfrequency stimulation in MPTP-treated monkeys. Eur J Neurosci $5: 382-389$.

Bergman H, Wichmann T, DeLong MR (1990) Reversal of experimental parkinsonism by lesions of the subthalamic nucleus. Science 249:1436-1438.

Bergman H, Wichmann T, Karmon B, DeLong MR (1994) The primate 
subthalamic nucleus. II. Neuronal activity in the MPTP model of parkinsonism. J Neurophysiol 72:507-520.

Campbell GA, Eckardt MJ, Weight FF (1985) Dopaminergic mechanisms in subthalamic nucleus of the rat: analysis using horseradish peroxidase and microiontophoresis. Brain Res 333:261-270.

Chesselet MF, Delfs JM (1996) Basal ganglia and movement disorders: an update. Trends Neurosci 19:417-422.

Chesselet MF, Weiss L, Wuenschell C, Tobin AJ, Affolter HU (1987) Comparative distribution of RNAs for glutamic acid decarboxylase, tyrosine hydroxylase and tachykinins in the basal ganglia: an in situ hybridization study in the rodent brain. J Comp Neurol 262:125-140.

Chesselet MF, Mercugliano M, Soghomonian JJ, Salin P, Qin Y, Gonzales C (1993) Regulation of glutamic acid decarboxylase gene expression in efferent neurons of the basal ganglia. Prog Brain Res 99:143-154.

Crossman AR (1989) Neural mechanisms in disorders of movement. Comp Biochem Physiol 93:141-149.

Delfs JM, Ciaramitaro VM, Parry TM, Chesselet MF (1995) Subthalamic nucleus lesions: widespread effects on changes in gene expression induced by nigrostriatal dopamine depletion in rats. J Neurosci 15:6562-6575.

DeLong MR (1990) Primate models of movement disorders of basal ganglia origin. Trends Neurosci 13:281-285.

Filion M (1979) Effects of interruption of the nigrostriatal pathway and of dopaminergic agents on the spontaneous activity of the globus pallidus neurons in awake monkey. Brain Res 178:425-441.

Filion M, Tremblay L (1991) Abnormal spontaneous activity of globus pallidus neurons in monkeys with MPTP-induced parkinsonism. Brain Res 547:142-151.

Fontaine B, Sassoon D, Buckingham M, Changeux JP (1988) Detection of the nicotinic acetylcholine receptor subunit mRNA by in situ hybridization at neuromuscular junction of 15-day-old chick striatal muscles. EMBO J 7:603-609.

Graybiel AM, Ragsdale CW (1978) Histochemically distinct compartments in the striatum of human, monkey and cat demonstrated by acetylcholinesterase staining. Proc Natl Acad Sci USA 75:5723-5726.

Guridi J, Herrero M-T, Luquin MR, Guillen J, Ruberg M, Vila M, Laguna J, Javoy-Agid F, Agid Y, Hirsch EC, Obeso JA (1997) Decreased GAD mRNA expression in internal pallidum and substantia nigra pars reticulata neurons after subthalamotomy. Brain, in press.

Hassani O-K, Mouroux M, Féger J (1996) Increased subthalamic neuronal activity after nigral dopaminergic lesion independent of disinhibition via the globus pallidus. Neuroscience 72:105-115.

Herrero M-T, Levy R, Ruberg M, Luquin MR, Villares J, Guillen J, Faucheux B, Javoy-Agid F, Guridi J, Agid Y, Obeso JA, Hirsch EC (1996) Consequence of nigrostriatal denervation and L-DOPA therapy on the expression of glutamic acid decarboxylase (GAD) messenger RNA in the pallidum. Neurology 47:219-224.

Hevner RF, Wong-Riley MTT (1990) Regulation of cytochrome oxidase protein levels by functional activity in the macaque monkey visual system. J Neurosci 10:1331-1340.

Hevner RF, Wong-Riley MTT (1991) Neuronal expression of nuclear and mitochondrial genes for cytochrome oxidase (CO) subunits analyzed by in situ hybridization: comparison with $\mathrm{CO}$ activity and protein. J Neurosci 11:1942-1958.

Hevner RF, Duff RS, Wong-Riley MTT (1992) Coordination of ATP production and consumption in brain: parallel regulation of cytochrome oxidase and $\mathrm{Na}^{+}, \mathrm{K}^{+}$-ATPase. Neurosci Lett 138:188-192.

Hevner RF, Wong-Riley MTT (1993) Mitochondrial and nuclear gene expression for cytochrome oxidase subunits are disproportionately regulated by functional activity in neurons. J Neurosci 13:1805-1819.

Hevner RF, Wong-Riley MTT (1995) A metabolic map of cytochrome oxidase in the rat brain: histochemical, densitometric and biochemical studies. Neuroscience 65:313-342.

Javoy-Agid F, Hirsch EC, Dumas S, Duyckaerts C, Mallet J, Agid Y (1990) Decreased tyrosine hydroxylase messenger RNA in the surviving dopamine neurons of the substantia nigra in Parkinson's disease: an in situ hybridization study. Neuroscience 38:245-253.

Johnson AE, Coirini H, Kälström L, Wiesel FA (1994) Characterization of dopamine receptor binding sites in the subthalamic nucleus. NeuroReport 5:1836-1838.

Kadenbach B, Jarausch J, Hartmann R, Merle P (1983) Separation of mammalian cytochrome $\mathrm{c}$ oxidase into 13 polypeptides by a sodium dodecyl sulfate-gel electrophoretic procedure. Anal Biochem 129:517-521.

Kadenbach B, Kuhn-Nentwig L, Buge U (1987) Evolution of a regulatory enzyme: cytochrome-c oxidase (complex IV). Curr Top Bioenerg 15:113-161.

Kincaid AE, Albin RL, Newman SW, Penney JB, Young AB (1992) 6-Hydroxydopamine lesions of the nigrostriatal pathway alter the expression of glutamate decarboxylase messenger RNA in rat globus pallidus projection neurons. Neuroscience 51:705-718.

Klockgether T, Turski L (1989) Excitatory amino acids and the basal ganglia: implications for the therapy of Parkinson's disease. Trends Neurosci 12:285-286.

Kreiss DS, Anderson LA, Walters JR (1996) Apomorphine and dopamine $D_{1}$ receptor agonists increase the firing rates of subthalamic nucleus neurons. Neuroscience 72:863-876.

Levy R, Herrero MT, Ruberg M, Villares J, Faucheux B, Guridi J, Guillen J, Luquin MR, Javoy-Agid F, Obeso JA, Agid Y, Hirsch EC (1995) Effects of nigrostriatal denervation and L-DOPA therapy on the GABAergic neurons of the striatum in MPTP-treated monkeys and Parkinson's disease: an in situ hybridization study of $\mathrm{GAD}_{67}$ mRNA. Eur J Neurosci 7:1199-1209.

Levy R, Hazrati LN, Herrero MT, Vila M, Hassani O-K, Mouroux M, Ruberg M, Asensi H, Agid Y, Féger J, Obeso JA, Parent A, Hirsch EC (1997) Re-evaluation of the functional anatomy of the basal ganglia in normal and parkinsonian states. Neuroscience, in press.

Miller W, DeLong MR (1987) Altered tonic activity of neurons in the globus pallidus and subthalamic nucleus in the primate MPTP model of parkinsonism. In: The basal ganglia II (Carpenter MB, Jayaraman A, eds), pp 414-427. New York: Plenum.

Mintz I, Hammond C, Féger J (1986) Excitatory effect of iontophoretically applied dopamine on identified neurons of the rat subthalamic nucleus. Brain Res 375:172-175.

Mitchell IJ, Clarke CE, Boyce S, Robertson RG, Peggs DE, Sambrook MA, Crossman AR (1989) Neural mechanisms underlying parkinsonian symptoms based upon regional uptake of 2-deoxyglucose in monkeys exposed to 1-methyl-4-phenyl-1,2,3,6-tetrahydropyridine. Neuroscience 32:213-226.

Mitchell IJ, Boyce S, Sambrook MA, Crossman AR (1992) A 2-deoxyglucose study of the effects of dopamine agonist on the parkinsonian primate brain. Brain 115:809-824.

Montgomery EB, Buchholz SR, Delitto A, Collins RC (1985) Effects of MPTP on basal ganglia physiology in monkeys. Soc Neurosci Abstr 11:1161.

Mouroux M, Féger J (1993) Evidence that the parafascicular projection to the subthalamic nucleus is glutamatergic. NeuroReport 4:613-615.

Mouroux M, Hassani O-K, Féger J (1995) Electrophysiological study of the excitatory parafascicular projection to the subthalamic nucleus and evidence for ipsi- and contralateral controls. Neuroscience 67:399-407.

Pan HS, Walters JR (1988) Unilateral lesion of the nigrostriatal pathway decreases the firing rate and alters the firing pattern of globus pallidus neurons in rat. Synapse 2:650-656.

Parent A, Lavoie B (1993) Dopaminergic innervation of the basal ganglia in normal and parkinsonian monkeys. In: Current concepts in Parkinson's disease research (Schneider JS, Gupta M, eds), pp 403-414. Toronto: Hans Ruber.

Porrino LJ, Burns RS, Crane AM, Palombo E, Kopin IJ, Sokoloff L (1987) Local cerebral metabolic effects of L-DOPA therapy in 1-methyl-4-phenyl-1,2,3,6-tetrahydropyridine-induced parkinsonism in monkeys. Proc Natl Acad Sci USA 84:5995-5999.

Porter RHP, Greene JG, Higgins Jr DS, Greenamyre JT (1994) Polysynaptic regulation of glutamate receptors and mitochondrial enzyme activities in the basal ganglia of rats with unilateral dopamine depletion. J Neurosci 14:7192-7199.

Ruskin DN, Marshall JF (1995) $\mathrm{D}_{1}$ dopamine receptors influence Fos immunoreactivity in the globus pallidus and subthalamic nucleus of intact and 6-OHDA-lesioned rats. Soc Neurosci Abstr 21:1906.

Sellal F, Hirsch E, Lisovoski F, Mutschler V, Collard M, Marescaux C (1992) Contralateral disappearance of parkinsonian signs after subthalamic hematoma. Neurology 42:255-256.

Soghomonian JJ, Chesselet MF (1992) Effects of nigrostriatal lesions on the levels of messenger RNAs encoding two isoforms of glutamate decarboxylase in the globus pallidus and entopeduncular nucleus of the rat. Synapse 11:124-133.

Soghomonian JJ, Pednault S, Audet G, Parent A (1994) Increased glutamate decarboxylase mRNA level in the striatum and pallidum of MPTP-treated primates. J Neurosci 14:6256-6265. 
Vernier P, Julien JF, Rataboul P, Fourrier O, Feuerstein C, Mallet J (1988) Similar time course changes in striatal levels of glutamic acid decarboxylase and proenkephalin mRNA following dopaminergic deafferentation in the rat. J Neurochem 51:1375-1380.

Vila M, Herrero M-T, Levy R, Faucheux B, Ruberg M, Guillen J, Luquin MR, Guridi J, Javoy-Agid F, Agid Y, Obeso JA, Hirsch EC (1996a) Consequences of nigrostriatal denervation on the GABAergic neurons of substantia nigra pars reticulata and superior colliculus in parkinsonian syndromes. Neurology 46:802-809.

Vila M, Levy R, Herrero M-T, Faucheux B, Obeso JA, Agid Y, Hirsch EC (1996b) Metabolic activity of the basal ganglia in parkinsonian syndromes in human and nonhuman primates: a cytochrome oxidase histochemistry study. Neuroscience 71:903-912.

Wichmann T, DeLong MR (1993) Pathophysiology of parkinsonian motor abnormalities. In: Advances in neurology, Vol 60 (Narabayashi H, Nagatsu T, Yanagisawa N, Mizuno Y, eds), pp 53-61. New York: Raven.
Wichmann T, Bergman H, DeLong MR (1994) The primate subthalamic nucleus. I. Functional properties in intact animals. J Neurophysiol 72:494-506.

Wong-Riley MTT (1979) Changes in the visual system of monocularly sutured or enucleated cats demonstrable with cytochrome oxidase histochemistry. Brain Res 171:11-28.

Wong-Riley MTT, Welt C (1980) Histochemical changes in cytochrome oxidase of cortical barrels after vibrissal removal in neonatal and adult mice. Proc Natl Acad Sci USA 77:2333-2337.

Wong-Riley MTT, Carroll EW (1984) Effect of impulse blockage on cytochrome oxidase activity in monkey visual system. Nature 307:262-264.

Wong-Riley MTT (1989) Cytochrome oxidase: an endogenous metabolic marker for neuronal activity. Trends Neurosci 12:94-101.

Wong-Riley MTT, Merzenich MM, Leake PA (1978) Changes in endogenous enzymatic reactivity to DAB induced by neuronal inactivity. Brain Res 141:185-192. 